\title{
Research on Anti-Factoring Financing Access Mechanism of Logistics Enterprises Under Supply Chain Finance Environment
}

\author{
Linan Wang and Yuting Sun* \\ School of Accounting, Jilin University of Finance and Economics, Changchun 130117, China \\ *Corresponding author.Email:1625695632@qq.com
}

\begin{abstract}
The influence of supply chain finance on the development of enterprises is increasing and the role of logistics enterprises is also changing. In order to ensure the smooth operation of the supply chain, it is imperative to standardize the anti-factoring financing access system for logistics enterprises. This paper puts forward the evaluation method of comprehensive credit level of logistics enterprises and formulates the development and management strategy of logistics enterprises.
\end{abstract}

Keywords: Logistics enterprise, Anti-factoring financing, Access permission mechanism.

\section{INTRODUCTION}

With the rapid development of economic globalization and information technology, commodity circulation in supply chain system is becoming more and more active. As an important member of the supply chain system, logistics enterprises are closely related to supply chain finance by connecting the material flow on the chain. Nowadays, with the continuous development of supply chain finance, the problem of financing difficulty emerges. In the case of capital shortage and capital turnover, it is difficult for logistics enterprises to fully cooperate with upstream and downstream enterprises, which leads to low efficiency of supply chain. In view of the difficult problem of financing logistics enterprises anti-factoring financing mode arises at the historical moment. Anti-factoring in logistics enterprises refers to that logistics enterprise raise funds to maintain normal operation in order to relieve capital shortage. He acts of obtaining funds through specific procedures on the basis of trade contracts between logistics enterprises and core enterprises. Logistics enterprises, core enterprises and financial institutions all participate in this process and core enterprises play a counter-guarantee role in the whole process. However, the entry threshold of logistics enterprises in the domestic market is low. Traditional, modern, large-scale and non-large-scale logistics enterprises can be called logistics enterprises, which make the operation order of many mixed logistics enterprises more chaotic. In view of this phenomenon, this paper expounds the necessity of standardizing the anti-factoring financing access system of logistics enterprises, puts forward the evaluation method of comprehensive credit level of logistics enterprises, and puts forward some Suggestions for the development of logistics enterprises.

\section{RESEARCH STATUS}

At present, there are few literatures on anti-factoring financing of logistics enterprises. Guo Tao in his article discusses the principles and advantages of accounts receivable financing [1]; the theory of rongtong warehouse proposed by Zhu Daoli and Luo Li builds a bridge between Banks and enterprises, and builds a third-party logistics enterprise platform. Combining the actual situation of logistics enterprises, the platform is perfectly integrated into the supply chain system to provide effective logistics services for enterprises and Banks; Lin Yifu found that with the expansion of logistics enterprises' market share and the improvement of work efficiency, free funds can no longer adapt to the development of enterprises, and external financing is very urgent;Peng Chunfang and Chen Lihong suggested giving full play to the credit of core enterprises and activating inventories to solve the problems in the 
supply chain, such as low information transparency and slow capital turnover, which can reduce the financing risk of enterprises.

\section{THE NECESSITY OF ESTABLISHING ANTI-FACTORING FINANCING ACCESS SYSTEM FOR LOGISTICS ENTERPRISES}

(1) Logistics enterprises connect the flow of materials in the whole chain, and serve as a bridge connecting enterprises at each node in the supply chain, providing logistics services for each enterprise in the supply chain. Logistics enterprises connect the flow of materials in the whole chain, and serve as a bridge connecting enterprises at each node in the supply chain, providing logistics services for each enterprise in the supply chain. Logistics enterprises provide logistics services for core enterprises, upstream and downstream enterprises, and have different degrees of contact with each enterprise in the supply chain[2].Therefore, logistics enterprises have a better understanding of material flow information between enterprises. Logistics enterprises need to give play to their advantages in this respect, integrate resources and information in the supply chain together, and provide guarantee for effective capital flow in the supply chain system.

(2) With the development of modern enterprises, logistics outsourcing has become a trend of choice. Most of the core enterprise can choose the is not very in ways such as transportation, warehousing outsourcing to "third party", the core enterprise to a great extent, optimize the information asymmetry problem, enhance the competitiveness of enterprises, can under the condition of the resource input is not increased, get double advantage of material transportation and regulation of movable property. Based on the financial needs of logistics customers and supported by the credit granting assets of core enterprises, this logistics business outsourcing model develops financing solutions and applies for financing from financial institutions. Logistics enterprises set up multiple storage points and are always in a state of multiple transport. They conduct 24-hour closed supervision over materials to ensure that the overall value of transported goods is higher than the minimum requirements of financial institutions.

(3) With the continuous progress and development of supply chain finance, logistics enterprises have been more and more deeply involved in the supply chain management of customers. Both the supplier and the buyer have a deep understanding of their credit status and business status. Logistics enterprise with its own logistics network information platform, grasp the transport supplies real-time field conditions, combining with financial and capital management system to complete the transportation supplies the coordinated control of information, and according to their own or cooperative enterprise need through the information communication mechanism, share the information to the parties involved, it is not only the establishment of information channel, also is the master of information.

(4) Logistics enterprises are the designers and implementers of logistics service schemes. In the practical application process, logistics enterprises will make service plans according to the characteristics of transportation materials, based on the signed contracts, and in combination with their own needs and customers' demands for materials and funds. The controller of the scheme is the logistics enterprise. During the implementation of the scheme, the logistics enterprise will adjust the transport and delivery plan according to the implementation of the plan and the operation of the customer enterprise. Logistics enterprises also need to coordinate the contradiction between upstream and downstream enterprises, so as to realize the combined operation of the whole supply chain and integrate the information flow, capital flow and logistics into one, which requires high management ability and skills.

In conclusion, a qualified logistics enterprise will not only have an impact on the development of the core enterprise, but also affect the development and progress of the entire supply chain. Core enterprise in supply chain, often with multiple third party logistics enterprise, logistics service itself is damaged in transit, such as loss of risk, so from a different Angle to evaluate the whole situation of logistics enterprises, try to choose good quality, high efficiency of the logistics enterprises as the object of financing, establishing a perfect system of logistics enterprise access, in order to reduce the risk factor of the capital recovery, ensure the normal operation of the entire supply chain.

\section{COMPREHENSIVE CREDIT EVALUATION OF LOGISTICS ENTERPRISES}

\subsection{The Basic Principles of Evaluating the Comprehensive Credit Level of Logistics Enterprises}

China's traditional credit rating system was established before the reform and opening up. Therefore, today's credit rating of logistics enterprises are mostly in accordance with the large enterprise loan credit survey model, focusing on the scale of business, based on the analysis of corporate financial statements, rather than growth. For the analysis of financial statements, enterprises are required to provide true and complete financial reports and statements. However, for most of the small and medium-sized logistics enterprises, the management model is not mature, financial health is not perfect, it is difficult to guarantee the authenticity of the financial information provided, it is difficult to judge the enterprise's real operating conditions and financial 
conditions, so in the logistics enterprise credit evaluation, can not rely too much on the analysis of financial statements and reports. In the assessment of logistics enterprises, more inclined to corporate repayment will and ability, but now the legal system is becoming more and more sound, corporate repayment will is not the main factor[3].In the financing process, the main problem is that the company is unable to repay the loan or the borrower's capital chain is broken, because the borrower is in the future repayment rather than now, so in the assessment process should pay more attention to the logistics enterprise cash ability and repayment ability, weakening the dependence on financial indicators, not limited to the analysis of historical data. In the credit evaluation of logistics enterprises, we should pay attention to the following.

Focus on future performance forecasts. Many small and medium-sized logistics enterprises due to the establishment of a short time, less money, small scale and other problems, there are natural defects in the market operation, low risk resistance, logistics enterprises must have enough development potential, in order to survive in the competitive market, therefore, a potential logistics enterprises should have both growth and development. The growth of enterprises means that enterprises have the ability to increase profits. Logistics enterprises should innovate and turn innovative projects into real economic benefits. They should find a balance between projects that can develop in the long run and projects with quick profits and quick results, and constantly turn innovative achievements into economic strength. The development of an enterprise refers to whether the new technology developed by the enterprise can bring benefits, increase market share and create cash flow if it has broad development prospects.

(2) Dilute financial indicators. The financial system of small and medium-sized logistics enterprises is not perfect, there are many loopholes, which makes the authenticity of the financial statements is difficult to guarantee. In the face of this situation, many scholars advocate in the credit rating of such enterprises, to focus on the analysis of non-financial factors. Weaken the influence of financial statements; mainly analyze the historical performance of enterprises. Specifically, according to the characteristics of different types of logistics enterprises, the financial factors and non financial factors together, to in-depth understanding of the future growth of the enterprise market, development prospects and competitive advantage, the qualitative elements of quantitative, understand the future development direction of the enterprise and the core technology, the logistics enterprise industry local objectivity evaluation, correctly judge the logistics enterprise future cash creation ability.

(3) Attach importance to enterprise performance evaluation. In the current credit evaluation systems for enterprises, Banks have begun to pay attention to the performance evaluation of enterprises. Compared with some large-scale logistics enterprises. Small and medium-sized logistics enterprises are faced with greater market risks and higher probability of default. In fact, whether the timely implementation of the agreement is to evaluate the level of enterprise credit a major factor. The cash flow can provide more accurate information and reflect the operation situation and solvency of logistics enterprises. The core enterprises and other enterprises in the supply chain can verify the cash flow of enterprises through statements, tax bills and other vouchers.

(4) Focus on different priorities for different situations. Although there are limited factors affecting the credit level of logistics enterprises, limited factors will play a key role. In order to build a high accuracy credit evaluation system, key factors should be found and key indicators under different markets should be highlighted. Logistics enterprises generally have two characteristics: One is the single operation project, small scale, simple organization, short borrowing time and small amount of money. Although the credit risk of logistics enterprises cannot be judged on this basis, the credit influencing factors of logistics enterprises are few and the credit rating is easy to be judged; Second, logistics enterprise's business in domestic markets, in different markets, logistics enterprise's capital investment and the degree of competition is different, have different market volatility and cyclical, growth and future prospects for development also very different in different areas, the situation of enterprise credit level is more or less have influence, this kind of enterprise's credit rating is complicated to determine. Therefore, different key evaluation indexes should be selected according to different types of logistics enterprises.

\subsection{The Main Influencing Factors of Credit Level Evaluation of Logistics Enterprises}

(1) Historical performance level. Mainly on the past existence of logistics enterprises during the financial situation, competitiveness and industry structure evaluation and analysis, from a macro point of view, analysis of logistics enterprises relative to the industry's development speed, operating conditions and development trends. We can draw lessons from the above financial situation analysis method, analysis of enterprise performance, in addition to qualitative analysis, but also quantitative calculation of logistics enterprise value drivers, such as return on investment capital, free cash flow, etc. [4].This model can improve the flexibility of enterprise management, but at the same time the enterprise credit rating also has a greater decisive role.

(2) Operator quality. For large-scale logistics enterprises, the quality of operators will have a profound 
impact on corporate culture, an excellent corporate culture can improve employee cohesion, enhance the core competitiveness of enterprises. In addition, in the face of fierce competition in the market and the complex market environment, operators to command and coordinate the normal operation of the enterprise, which not only consumes physical strength, the operator's mental activity is also a test; And small and medium-sized logistics enterprises smaller, in general, only 1-2 people engaged in business management, so that business decision-making and management rights are concentrated in the operator's body. The evaluation of the quality of the operators should mainly examine the level of qualifications, historical credit records, experience, performance records, etc.

(3) The ability to repay loans or loans. Repayment ability is the ability that must be examined when evaluating the level of credit. After all, it is the ability of an enterprise to obtain cash. Only when a logistics enterprise earns cash in the course of operation, can it have repayment ability. In this factor, in addition to examining the profitability of the enterprise, it is also necessary to examine how much cash obtained is required to repay loans and loans, and a large proportion of repayment can prove the repayment ability of the enterprise. In the construction of the credit evaluation system, it is also necessary to consider whether the annual debt service and interest can match the enterprise's ability to obtain cash, if not, it is necessary to reduce the enterprise's credit rating.

(4) Producing and operating status. The production and operation status of an enterprise can reflect the enterprise's sustainable operation and development ability, and its judgment method is to look at the operation status of the enterprise, whether there is a big change in the same period compared to the same period. For logistics enterprises, it is necessary to compare whether the tax amount has changed compared with the same year, and whether the company's vehicle fuel consumption and mileage are reasonable compared with other enterprises. The investigation of production and operation can also reflect the management ability of business owners.

(5) Innovation capability and industry risk. The industry risks of logistics enterprises in the domestic market mainly lie in the constantly changing market and enterprise development prospect. Therefore, it is necessary to analyze the enterprises in the context of the general trend of industry development and the changes in the market. In addition, we should also consider the impact of major domestic economic policy adjustments and relevant laws and regulations. Nowadays, with the rapid development of science and technology, the innovation ability of an enterprise has become the main factor to evaluate the development ability of an enterprise. Logistics enterprises should evaluate their innovation ability from three aspects: $r \& d$ investment rate, achievement conversion efficiency and ratio of new product sales to total revenue. In addition, attention should also be paid to the stability of the innovation ability, which can guarantee the sustainable operation ability of the enterprise. If there are major events in the enterprise, such as the introduction or loss of new technologies and talents, the credit level of the enterprise will be affected.

\section{DEVELOPMENT STRATEGIES OF LOGISTICS ENTERPRISES IN SUPPLY CHAIN FINANCE ACTIVITIES}

(1) Pay attention to enterprise credit and own brand construction. In the process of development, logistics enterprises should put corporate image and corporate credit construction in the first place. The premise that the supply chain can run smoothly is that the enterprises in the supply chain have high credibility. If the enterprise lacks credibility, it will not only affect the normal operation of the enterprise, but also be hindered in financing. Only by improving the credit, Banks or other financial institutions can finance enterprises, inject capital into enterprises at ease, and ensure the smooth flow of funds in the supply chain.

(2) Improve the ability of information collection and analysis. Logistics enterprises should provide traditional logistics services as the basis, the use of modern information systems to enhance information collection and analysis capabilities, to further expand their own logistics service network, and actively participate in the supply chain operation process. By mining data to identify the hidden problems in the operation, to provide support for financial institutions' financial decision-making, effective integration of information resources, customer resources, closely monitoring the operation of enterprises in the supply chain, only in this way, can increase the impact on the supply chain capital flow in the development.

(3) Track and evaluate the operating conditions. Analysis of the operating conditions and existing problems, so that the operating performance, service quality, technology development, customer satisfaction and performance of the real-time monitoring, and scientific assessment, once the possible problems in a timely manner to inform the associated enterprises to prevent and improve. Logistics enterprises should formulate corresponding emergency measures for possible supply chain financial risks.

(4) Conduct business design innovation. In the current products and services can not meet the needs of customers and the market, it is necessary to improve and innovate the original products and services, supply chain finance is essentially a business innovation. Through business innovation to improve brand 
awareness, improve customer satisfaction and market recognition.

\section{CONCLUSION}

Combined with the actual situation and research status of logistics enterprises, the anti-factoring financing of logistics enterprises is analyzed. At present, logistics enterprises have not fully adapted to the development trend of supply chain finance, and the ability to control supply chain funds is not enough. In the anti-factoring business, financial institutions often require the core business to assess the third party logistics enterprises. However, it is difficult to meet the requirements of financing subject evaluation by only relying on the evaluation of logistics enterprises by the core enterprises. Therefore, we should improve the anti-factoring financing access system of logistics enterprises, improve the access requirements of logistics enterprises, reduce the risk of factoring capital recovery, eliminate bad logistics enterprises, and ensure the smooth operation of the whole supply chain.

\section{REFERENCES}

[1] Guo Tao. Accounts Receivable financing, a new financing channel for smes $[\mathrm{J}]$. Economist, 2005(02):152-153.

[2] Wang Chuandong. Research on Credit Guarantee of Small and Medium-sized Enterprises [D]. Shandong Agricultural University, 2006.

[3] Yang Fei, Zhou Shipeng. Research on credit rating of small and medium-sized logistics enterprises [J]. Logistics engineering and management, 2017, 39(05):12-14+23.

[4] Wang yubo. Research on logistics enterprise development based on supply chain finance $[\mathrm{J}]$. Railway transport and economy, 2013, 35(06):80-83. 